\title{
Fındık yağının kozmetik ürünlerde kullanımı
}

\section{Derya ÇIÇEK POLAT ${ }^{(D)} 1$}

${ }^{1}$ Ankara Üniversitesi, Eczacılık Fakültesi, Farmasotik Botanik Anabilim Dalı, Ankara

Alınıs tarihi: 10 Nisan 2019, Kabul tarihi: 10 Aralık 2019

Sorumlu yazar: Derya ÇİÇEK POLAT, e-posta: polatd@ankara.edu.tr

\section{$\ddot{0} \mathbf{z}$}

Son zamanlarda insanlar her açıdan doğala yönelmektedir, bu nedenle kozmetik ürünlerde de bitkisel kaynaklı ürünler daha çok tercih edilmektedir. Kozmetik ürünlerin içerisinde bitkisel ekstre, fraksiyon, sabit yağ, uçucu yağ yada saf madde bulunabilir. Tohumlardan elde edilen yağlar çoğu kozmetik ürünlerin bileşimine girmektedir. Bunlardan biri de findık tohumlarından elde edilen yağlardır. Fındık yağı nemlendirici, yenileyici ve canlandırıcı özellikleri nedeniyle, bazı kozmetik ürünlerin bileşimine girmektedir. Anavatanı Türkiye olan fındık, insanların günlük diyetlerinde yer alan önemli besin maddesi olmasının yanı sıra elde edilen fındık yağı çeşitli amaçlarla kullanılmaktadır. $\mathrm{Bu}$ çalışmada, fındık ve fındık yağının fitokimyasal içeriği ve kozmetiklerde findık yağı kullanımının nedenleri hakkında bilgi verilmiştir. $\mathrm{Bu}$ çalışma sonucunda findık ihracatında birinci sırada olan ülkemizin, uygun koşullarda üreteceği fındık yağı ile kozmetik ürünler için gerekli hammaddeyi sağlayabileceği düşünülmektedir.

Anahtar kelimeler: Corylus sp., fındık, fındık yağı, kozmetikler

\section{Use of hazelnut oil in cosmetic products}

\begin{abstract}
In recent days people have turned to nature in every aspect, so in the cosmetic products, herbal products are more preferred. Cosmetic products may contain plant extract, fraction, fatty oil, essential oil or active substance. Oils obtained from seeds are included in the composition of most cosmetic products. One of them is oil obtained from hazelnut seeds. Due to its
\end{abstract}

moisturizing, regenerating and invigorating properties, hazelnut oils enters into the composition of some cosmetic products. Hazelnut, which is naturally grown in Turkey, is one of the important nutrients in the daily diets of people and hazelnut oil is also used for various purpose. In this study, information is given about the phytochemical content of hazelnut and hazelnut oil and the reasons for using hazelnut oil in cosmetics. As a result of this study, it is thought that our country, which is the first in hazelnut export, can provide the necessary raw material for the cosmetic products with hazelnut oil which will be produced under appropriate conditions.

Key words: Corylus sp., hazelnut, hazelnut oil, cosmetics

\section{Giriş}

Kozmetik, insan vücudunun epiderma, saçlar, dudaklar gibi değișik dış bölümlerine, diş ve ağız mukozasına uygulanmak üzere hazırlanmıș, amacı bu kısımları temizlemek, koku vermek, görünümünü düzeltmek, korumak veya iyi bir durumda tutmak olan bütün preparatlara veya maddelere denir (Kışlalıoğlu, 2004; Çomoğlu, 2012; Hetta, 2016). Kozmetik ürünler içerisinde yer alan bitkisel bileșikler ve standardize edilmiș bitki ekstrelerinin hepsine fitokozmetikler adı verilmektedir (Koluman ve Süzgeç-Selçuk, 2016). Sentetik bazlı ürünlerin kullanımının neden olduğu bir çok hastalık ve yan etkilerden dolayı günümüzde her konuda doğala yönlenilmektedir. Bu durum kozmetik ürünlerde de karşımıza çıkmaktadır. Bitkiler temel olarak, antioksidan, antienflamatuar, antiseptik ve antimikrobiyal etkileri gibi çeşitli özelliklerden dolayı kozmetik formülasyonlara eklenmektedir 
(Fatima ve ark., 2013; Koluman ve Süzgeç-Selçuk, 2016; Algin-Yapar, 2018). Eczanelerde satılan fitokozmetik ürünler içerisinde 400'e yakın bitkinin bulunduğu tespit edilmiştir. Bitkilerin fitokozmetik ürünlere katılım sayısına bakıldığında en çok deriye uygulanan preparatlarda bitkisel ürün kullanıldığı görülmüştür (Koluman ve Süzgeç-Selçuk, 2016).

Fitokozmetik ürünlerin içerisine giren bitkisel kaynaklı ürünlerden biri de cildi nemlendirme ve koruma potansiyele sahip çeșitli fitokimyasal bileșikler içeren fındık yağıdır (Athar ve Nasir, 2005). Eczanelerde satılan fitokozmetik ürünlere bakıldığında el ve vücut kremlerinin, göz çevresi krem ve serumlarının Corylus americana Marsh. ve Corylus avellana L. türlerine ait yağları içerdiği görülmüștür (Koluman ve Süzgeç-Selçuk, 2016).

$\mathrm{Bu}$ çalışmada ülkemizde hem doğal olarak yetişen hem de kültürü yapılan fındık hakkında fitokimyasal içerik, kullanım amacı ve kozmetik alanındaki yeri hakkında bilgiler verilmiştir.

\section{Fındık ve yapılan fitokimyasal çalışmalar}

Findık (Corylus sp.), Betulaceae familyasına ait dünyada 22 türle temsil edilen bir bitki cinsidir (Plantlist, 2019). Bu bitkinin kültürü yapılan türlerinin anavatanı Türkiye'dir. Kültürü yapılan türler Corylus avellana L. (adi findık), C. colurna L. (Türk findığı) ve C. maxima Mill. (Lâmbert veya Kan fındığı)'dır (Doğanay, 2005; Bars, 2017). Dünya üretiminde Türkiye birinci sırada yer almaktadır (Kornsteiner ve ark., 2006; Bars, 2017; Michalak ve Kieltyka-Dadasiewicz, 2019; Turan, 2019a).

Fındık genellikle insanların günlük diyetlerinde tükettiği bir besin maddesidir. Halk arasında, fındık ve bal karıștırılarak elde edilen macun eskiden beri kuvvet verici ve cinsel gücü arttırıcı olarak kullanılmaktadır. Bunun yanında yapraklarının da diğer idrar arttırıcı bitkiler ile birlikte demleme usülü çayı (\%2-5) yapılarak idrar söktürücü olarak kullanıldığı bilinmektedir (Baytop, 1999). Yapılan araştırmalarda findığın önemli derecede vitamin, mineral ve polifenol kaynağı olduğu saptanmıştır (Michalak ve Kieltyka-Dadasiewicz, 2019). Fındık yağının içerdiği yağ asitleri fındığın yetiştiği bölgeye göre değişiklik göstersede, yüksek oranda palmitik (\%3.8), palmitoleik (\%37.0), stearik $(\% 1,7)$, oleik (\%84.5), linoleik (\%10), dokosenoik (\%3.4), linolenik (\%1.1) ve eikosaenoik asit (\%4.6) içerdiği bilinmektedir (Turan, 2018). Bu değerler findığın toplandığı bölge, toplandığı zaman ve kurutma yöntemlerine göre değişiklik gösterebilmektedir (Turan, 2019b).
Fındığın, vücudumuzda bazı metabolik aktivitelerde görevli olan potasyum, fosfor, kalsiyum, magnezyum, mangan, demir, bakır ve çinko gibi mineraller açısından da diğer bitkisel kaynaklı gıdalara oranla daha zengin olduğu çalışmalarda gösterilmektedir (Özdemir ve ark., 1998; Özdemir ve ark., 2001; Michalak ve Kieltyka-Dadasiewicz, 2019). E vitamini (22.4 mg/100g) açısından zengin olduğu bilinen fındığın günlük $40 \mathrm{~g}$ tüketimi E vitamini ihtiyacını karşıladığı ve bu özelliği nedeniyle önemli bir antioksidan kaynağı olduğu belirtilmektedir (Alasalvar ve ark., 2003). Flavonoitler (flavan-3-ol, kateşin, epikateşin, myrisetin-3-ramnozit ve kersetin-3-ramnozit), fenolik asitler (6.21-14.31 $\mathrm{mg} / 100 \mathrm{mg}$ ) (gallik, kafeik, ferulik, p-kumarik ve sinaptik asit), tanen (941-3163 mg CE/100g) ve stilben (reveratrol) içerdiği de yapılan çalışmalarda gösterilmiştir (Özdemir ve ark., 1998; Thompson ve ark., 2006; Pelvan ve ark.,2012; Chang ve ark., 2016; Michalak ve Kieltyka-Dadasiewicz, 2019).

\section{Kozmetik ürünlerde fındık yağı}

Emoliyanlar kozmetiklere cildi yumuşatmak ve pürüzsüzleștirmek için eklenen yardımcı maddelerdir. Yaygın olarak kullanılan emoliyanlar ise bitkilerden elde edilen sabit yağlardır (Tırnaksız, 2010). Fındık yağı yüksek oranda içerdiği fenolik bileşiklerden dolayı güçlü antioksidan etkiye sahip olduğu bilinmektedir (Shahidi ve ark., 2007; Michalak ve Kieltyka-Dadasiewicz, 2019). Yaşlanma karşıtı kozmetik ürünlerin içerisinde genellikle antioksidan maddeler tercih edilmektedir. Aynı şekilde içerdiği retinol, vitamin $\mathrm{E}$ ve diğer antioksidan maddeler nedeniyle findık yağı yaşlanma karşıtı ürünlerin bileșimine girebilmektedir. (Alasalvar ve ark., 2003; Türsen, 2006). İçerdiği tanenler nedeniyle astrenjen ve antibakteriyel etkiye sahiptir (Jiang ve ark., 2014; Michalak ve Kieltyka-Dadasiewicz, 2019). Astrenjen ve antibakteriyel özelliği nedeniyle yüz temizleme ürünlerinde yer alabilmektedir. Fındık yağı, nemledirici etkinin uzun süreli olmasını sağlayan zengin lipit içeriğine sahip olması nedeniyle de nemlendirci, yenileyici ve canladırıcı olarak cilt bakım ürünlerinde bulunabilmektedir (Athar ve Nasir, 2005).

Eczanelerde satılan kozmetik ürünler üzerinde yapılan araștırmada C. americana Marsh. türüne ait fındık yağının cilt yenileyici serumlarının içinde, $C$. avellana L. türüne ait findık yağının da krem, serum, vücut yağı ve göz çevresi kremleri içerisinde yer 
aldığı görülmektedir (Koluman ve Süzgeç-Selçuk, 2016).

\section{Sonuçlar ve Tartışma}

İnsanların son yıllarda sentetik maddelerden uzaklaşma ve doğala yönelme isteği kozmetik ürünlerde de bitkisel kaynaklı ürünlerin tercih edilmesine neden olmaktadır. Bitkisel kaynaklı ürünlerin sentetik ürünlerden daha güvenli olduğu algısı fitokozmetik ürünlere talepleri arttırmaktadır. Ancak tıpkı insan sağlığı için kullanılan preparatlar gibi bitkisel kozmetik ürünler üzerinde de onların güvenli hammadde ve güvenli kullanımını sağlayacak çalışmaların yapılması gerekmektedir.

Çeşitli fındık türlerinden elde edilen yağlarla ilgili bilimsel literatürlere baktığımızda, kozmetik bileşeni olarak kullanılan, bazı kozmetik ürünlerin içerisinde gördüğümüz fındık yağıyla ilgili çalışmaların yetersiz olduğu görülmüştür. Her ne kadar bazı çalıșmalar $C$. americana ve $C$. avellana yağlarının güvenilir olduğunu gösterse de dermal irritasyon ve duyarlılık, UV emilimi, 28 günlük dermal toksisite ve genotoksiste çalışmalarının çoğaltılması gerektiğ düşünülmektedir (Madhaven, 2001; Burnett ve ark., 2017; Michalak ve Kieltyka-Dadasiewicz, 2019). Özellikle de bu çalışmaların ülkemizde yetişen ve kültürü yapılan türler üzerinde de yapılması gerektiği önerilmektedir.

Fındık üretiminde dünya üzerinde birinci sırada olan Türkiye, fındık ihracatında en büyük paya sahiptir (Bars, 2017; Oparnica ve ark., 2017). Fındık yağı yüksek oranda besleyici ve enerji bakımından zengindir. $\mathrm{Bu}$ özelliklerinin yanında, ilaç endüstrisi ve kozmetik alanında da önemli bir hammadde görevi görmektedir (Oparnica ve ark., 2017; Dobhal ve ark., 2018).

Fındık ve findık yağı üretiminin sadece besin maddesi olarak değil, kozmetik ürünlerde de kullanılabilecek standartlarda üretilmesi de ülkemiz için yeni bir gelir kaynağı yaratabilir. Gerekli bilimsel araştırmalar yapıldıktan sonra uygun koşullarda üretilen fındık yağı, kozmetik ürünler açısından da dünya genelindeki büyük kozmetik şirketlerine gerekli ham madde kaynağını sağlayabilir.

\section{Kaynaklar}

Alasalvar, C., Shahidi, F., Liyanapathirana, C. M., Ohshima, T., 2003. Turkish tombul hazelnut (Corylus avellane $\mathrm{L}$.): 1 . compositional chracteristics. Journal of Agricultural and Food Chemistry, 51(13): 37903796 .
Algın-Yapar, E., 2018. Fitokozmetikler. Türk Farmakope Dergisi, 3(1): 110-116.

Athar, M., Nasir, S.M., 2005. Taxonomic perspective of plant species yielding vegetable oils used in cosmetics and skin care products. African Journal of Biotechnology, 4(1): 36-44.

Bars, T., 2017. Fındık Raporu, Gıda, Tarım ve Hayvancılık Bakanlığı, Tarımsal Ekonomi ve Politikalar Geliştirme Enstitüsü (Web sayfası: https://arastirma.tarimorman.gov.tr/tepge/Menu/ 37/Urun-Raporlari), (Erişim tarihi: Erişim tarihi: 02.12.2019)

Baytop, T., 1999. Türkiye'de Bitkiler ile Tedavi (Geçmişte ve Bugün). Nobel Tıp Kitapevleri, Çapa, İstanbul, $480 \mathrm{~s}$.

Burnett, C.L., Fiume, M.M., Bergfeld W.F., Belsito, D.V., Hill, R.A., Klaassen C.D., Liebler, D., Marks, J.G., Shank, R.C., Slaga, T.J., Snyder, P.W., Andersen, F.A., 2017. Safety assessment of plant-derived fatty acid oils. International Journal of Toxicology, 36(3): 51-129.

Chang, S.K., Alasalvar, C., Bolling, B.W., Shahidi, F., 2016. Nuts and their co-products: The impact of processing (roasting) on phenolics, bioavailability, and health benefits - A comprehensive review. Journal of Functional Food, 26(1): 88-122.

Çomoğlu, T., 2012. Kozmetikler. Marmara Pharmaceutical Journal,16(1): 1-8.

Dobhal, K., Singh, N., Semwal, A., Negi, A., 2018. A brief review on: Hazelnuts. Internationl Journal of Recent Scientific Research, 9(1): 23680-23684.

Doğanay, S., 2005. Trabzon ilinde fındık tarımı. Eastern Geographical Review, 10(13): 233-251.

Fatima, A., Alok, S., Agarwal, P., Singh, P.P., Verma, A., 2013. Benefits of herbal extracts in cosmetics: A review. International Journal of Pharmaceutical Sciences and Research, 4(10): 3746- 3760.

Hetta, M.H., 2016. Phytocosmetics in Africa. International Journal of Phtocosmetics and Natural Ingredients, 3(1): $1-7$

Jiang, Y., Gong, N.N., Matsunami, H., 2014. Astringency: a more stringent definition. Chemical Senses, 39(6): 467-469.

Kışlalığlu, S., 2004. "Kozmetoloji Bilimi,3-9". Kozmetik Bilimi (Ed: Yazan, Y.). Nobel Tıp Kitabevi, İstanbul, $416 \mathrm{~s}$.

Koluman, A., Süzgeç-Selçuk, S., 2016. Eczaneler'de fitokozmetikler. Marmara Pharmaceutical Journal, 20(1): 
Kornsteiner, M., Wagner, K.H., Elmadfa, I., 2006. Tocopherols and total phenolics in 10 different nut types. Food Chemistry, 98(2): 381-387.

Madhaven, N., 2001. Final report on the safety assessment of Corylus avellana (Hazel) seed oil, Corylus americana (Hazel) seed oil, Corylus avellana (Hazel) seed extract, Corylus americana (Hazel) seed extract, Corylus avellana (Hazel) leaf extract, Corylus americana (Hazel) leaf extract, and Corylus rostrata (Hazel) leaf extract. International Journal of Toxicology. 20(1): 15-20.

Michalak, M., Kieltyka-Dadasiewicz, A., 2019. Nut oils and their dietetic and cosmetic significance: a review. Journal of Oleo Sciences, 68(2): 111-120.

Oparnica, C., Radivojevic, D., Vulic, T., Djordjevic, B., 2017. Chemical composition of hazelnut (Corylus spp.) cultivars. Annals of the University of Craiova Agriculture, Montanology, Cadastre Series, 47(1): 477-480.

Özdemir, F., Topuz, A., Doğan, Ü., Karkacıer, M., 1998. Fındık çeşitlerinin bazı fiziksel ve kimyasal özellikleri. Gıda, 23(1): 37-41.

Özdemir, M., Açkurt, F., Kaplan, M., Yıldız, M., Löker, M., Gürcan, T., Biringen, G., Okay, A., Seyhan, F.G., 2001. Evaluation of new Turkish hybrid hazelnut (Corylus avellana L.) varieties: fatty acid composition, $\alpha$ tocopherol content, mineral composition and stability. Food Chemistry, 73 (4): 411-415.

Plant list, 2019. (Web sayfası: http://www.theplantlist.org (Erişim tarihi: 02.12.2019)
Pelvan, E., Alasalvar, C., Uzman, S., 2012. Effects of roasting on the antioxidant status and phenolic profiles of commercial Turkish hazelnut varieties (Corylus avellana L.). Journal of Agricultural and Food Chemistry, 60(5): 1218-1223.

Shahidi, F., Alasalvar, C., Liyana-Pathirana, C.M., 2007. Antioxidant phytochemicals in hazelnut kernel (Corylus avellana L.) and hazelnut by products. Journal of Agricultural and Food Chemistry, 55(4): 1212-1220.

Thompson, L.U., Boucher, B.A., Liu, Z., Cotterchio, M., Kreiger, N., 2006. Phytoestrogen content of foods consumed in Canada, including isoflavones, lignans, and coumestan. Nutrition and Cancer, 54(2): 184201.

Tırnaksız, F., 2010. “Cilt Bakım Ürünleri, 91-123”. Kozmetik Bilimi (Ed. Y. Yazan). Nobel Tip Kitapevleri, İstanbul, $416 \mathrm{~s}$.

Turan, A., 2018. Effect of drying methods on fatty acid profile and oil oxidation of hazelnut oil during storage. European Food Research and Technology, 244(12): 2181-2190.

Turan, A., 2019a. Effect of drying on the chemical composition of Çakıldak (cv) hazelnuts during stroge. Grasas Y Aceites, 70(1): 1-12.

Turan A., 2019b. Effect of drying methods on fatty acid profile of hazelnut (Corlus avelna L.): A review. Turkish Journal of Agriculture- Food Science and Technology, 7(11):1780-1784.

Türsen, Ü., 2006. Deri yaşlanmasının topikal ajanlarla önlenmesi. Dermatose, 4(1): 267-283. 